\title{
Clinical outcome of post-abortion intrauterine contraceptive device insertion
}

\author{
Rupali Dewan, Priyanka Rani*
}

Department of Obstetrics and Gynecology, VMMC and Safdarjung Hospital, New Delhi, India

Received: 12 March 2020

Accepted: 22 April 2020

\section{*Correspondence:}

Dr. Priyanka Rani,

E-mail: priyankarani4121989@gmail.com

Copyright: (C) the author(s), publisher and licensee Medip Academy. This is an open-access article distributed under the terms of the Creative Commons Attribution Non-Commercial License, which permits unrestricted non-commercial use, distribution, and reproduction in any medium, provided the original work is properly cited.

\begin{abstract}
Background: Clinical outcome of post abortion IUCD varies according to type of abortion, method of abortion and period of abortion. There is paucity of Indian literature regarding factor affecting clinical outcome of post-abortal intrauterine contraceptive device insertion. This study was conducted to evaluate clinical outcome of post abortion intrauterine contraceptive in terms of acceptability, safety and continuation rate.

Methods: A prospective cohort study where 112 patients over period of 18 months (November 2017 to April 2019) were included in study done at VMMC and Safdarjung Hospital, New Delhi, India.

Results: Total 112 patients recruited. Their age ranges from 26-30 years. Mean age of women were 28.11 \pm 4.51 years. Majority of women who underwent IUCD insertion were para2. Regardless of type of IUCD, the most common side effects associated with copper wearing IUCD were change in amount of menstrual flow. Two cases of PID after CuT380A insertion and one case of PID after cu375. No perforation occurred. Continuation rate were $86.79 \%$. Satisfaction rate were $82.14 \%$.

Conclusions: There is higher rate of continuation and satisfaction among women who had undergone immediate post abortion OUCD insertion. Early insertion of IUCD after abortion is safe, effective and well tolerated by women. Clinical outcome of post abortion is not affected by type of copper containing IUCD i.e., Cu380A and Cu375.
\end{abstract}

Keywords: Continuation, Immediate insertion, Intrauterine device, Post abortion contraception, Satisfaction

\section{INTRODUCTION}

Globally including India, a large proportion of abortions are repeat abortion. The global disparity in access to contraceptive immediately following abortion for new strategies of ensuring access to effective, convenient and safe family planning method. ${ }^{1}$

The return of fertility after an abortion is good and $83 \%$ of women who had an abortion ovulate during the first menstrual cycle following the abortion and ovulation may occur as early as 8-10 days after an induced abortion. ${ }^{2}$ After induced abortion, a women's motivation to use contraception may be high and for women who had limited access to a clinician, abortion care may provide a unique opportunity to address a women's need for contraception. $^{3}$

A post abortion contraceptive method should be effective, long-acting, reversible and convenient to use. The immediate Intrauterine contraceptive device insertion would provide the women an opportunity to have an effective contraceptive method earlier, before resumption of sexual activities. In addition, insertion of an IUCD immediately after abortion may avoid discomfort related to insertion.

The objective of the study is to compare clinical outcome of $\mathrm{Cu}$-IUCD insertion post abortion with respect acceptability, expulsion/removals and complication. 
Furthermore, authors also aim to investigate the various factor affecting the clinical outcome of post abortion IUCD i.e. type of abortion, period of gestation, type of IUCD and method of abortion.

\section{METHODS}

It is a prospective cohort study of women seeking medical/surgical termination of pregnancy or underwent management for spontaneous abortion in department of obstetrics and gynecology VMMC and Safdarjung hospital and desirous of CuT380A or Cu375 IUCD as post abortion contraceptive. Total 112 women included in study from November 2017 to April 2019. Women divided into two groups according type of abortion (spontaneous/induced). Sub group analysis was done according to;

- $\quad$ Type of IUCD (CuT380A/Cu375)

- Method of abortion (medical/surgical)

- Period of gestation ( $1^{\text {st }}$ trimester/ $2^{\text {nd }}$ trimester $)$.

\section{Inclusion criteria}

- Women underwent copper containing IUCD insertion as method of contraception after complete abortion

- Willing to participate in the study and return for follow-up visits for 6 months.

\section{Exclusion criteria}

- Clinical examination/USG suggestive of retained products of conception

- Clinical/laboratory evidence of septic abortion

- Post abortion hemorrhage

- Abnormality of uterus or distortion of uterine cavity

- Pelvic inflammatory disease

- WHO MEC category $3 / 4$ for IUCD insertions.

A woman who desired IUCD as contraceptive method where be counselled regarding advantages, limitation, effectiveness and side effects of IUCD, Copper380A/Cu375 providing contraception for 10 years $/ 5$ years respectively, were inserted as preferred by the women. Eligible women were enrolled for the study. Written informed consent were taken from all women seeking copper IUCD after abortion. pre and post abortion examination and investigation done and recorded. IUCD was inserted by "no touch withdrawal technique". Each patient was given a bleeding diary with standardized definition of bleeding, spotting and no flow days. Women were called for follow up on $15^{\text {th }}$ day, 1 month, 3 month and 6 months.

\section{At each visit following observation made}

- Speculum examination were performed to assess if IUCD is in place and to rule out expulsion
- USG pelvis were done to exclude expulsion in case of non-visualization of IUCD string on per speculum examination

- Occurrence of pregnancy

- Pelvic infection

- Request for removal and reason for removal

- Any complaints and queries.

If at any visit there were finding suggestive of pelvic inflammatory disease appropriate treatment as per NACO guidelines were given. IUCD removal done in case of excessive bleeding, pain expulsion, pregnancy or subject's request.

\section{Following outcome were studied at end of study}

\section{Primary outcome}

- Continuation rate of IUCD at 6 months

- Safety profile: hemorrhage, perforation, infection

- Acceptability.

Secondary outcome

- Reason of discontinuation

- Expulsion/removal with reason

- Bleeding pattern

- Pain.

\section{Statistical analysis}

Baseline demographic data were compared according to treatment group to assess for significant difference using Fisher's exact test or Chi-square test for categorical data Student t-test for continuous data. The data were entered in MS excel spread sheet and analysis were done using statistical package for social science version 21.0 (SPSS).

\section{RESULTS}

All patients who received post abortion IUCD from November 2017 to April 2019 were included in analysis. During study period total 112 post abortion IUCD insertion done. Out of 112, 104 insertion done after $1^{\text {st }}$ trimester abortion and 8 insertion done after $2^{\text {nd }}$ trimester abortion. 60 women opted for CuT380A and 52 opted for $\mathrm{Cu} 375$. At end of 6 month out of 112, 92 women continued IUCD (Figure 1).

On analysis of all demographic variables there were no significant difference between those who choose CuT380A or Cu375. Majority $(48.31 \%)$ of women belong to age group 26-30 years. Mean age of women were $28.11 \pm 4.5$ years. Majority of women who underwent IUCD insertion were para2. Out of 112, 52 women underwent immediate insertion of IUCD. Majority $(92.85 \%)$ of IUCD insertion were perceived to be easy by provider. 


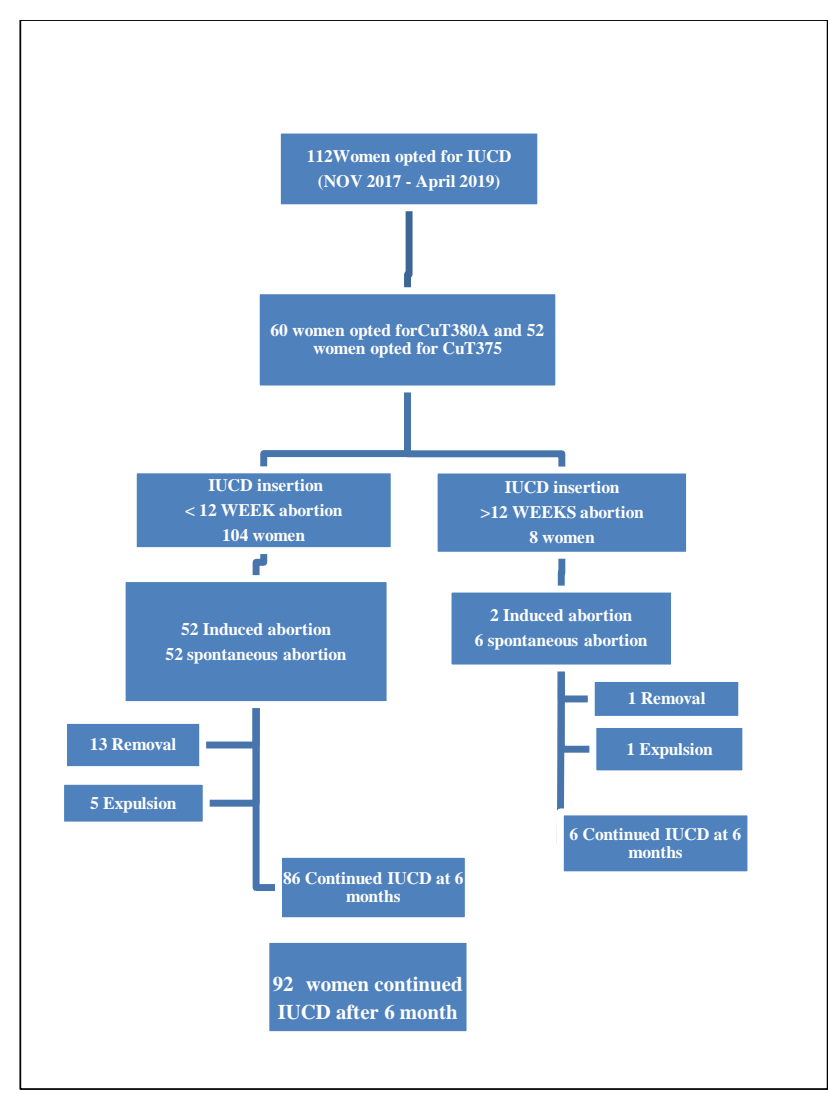

Figure 1: Flow chart of study participants.

Regardless of type of abortion, period of gestation, type of IUCD most common side effect with copper bearing IUCD are change in amount of menstrual blood flow and related cramps. No perforation occurred. Two (1.78\%) women reported with intrauterine pregnancy with IUCD in situ at 6 months follow-up and opted for medical termination of pregnancy along with IUCD removal. Strings were not visualized in 3 cases at 3 month and 3 cases at 6 months follow-up. Continuation rate was $86.79 \%$ at 6 months follow-up. There were 13 case of removal and 5 case of expulsion after 1st trimester IUCD insertion while 1 case of removal and 1 case of expulsion after $2^{\text {nd }}$ trimester IUCD insertion. There were 9 cases of removal and 4 cases of expulsion following induced abortion whereas 5 cases of removal and 2 cases of expulsion following spontaneous abortion insertion. This difference is statistically insignificant (Figure 2).

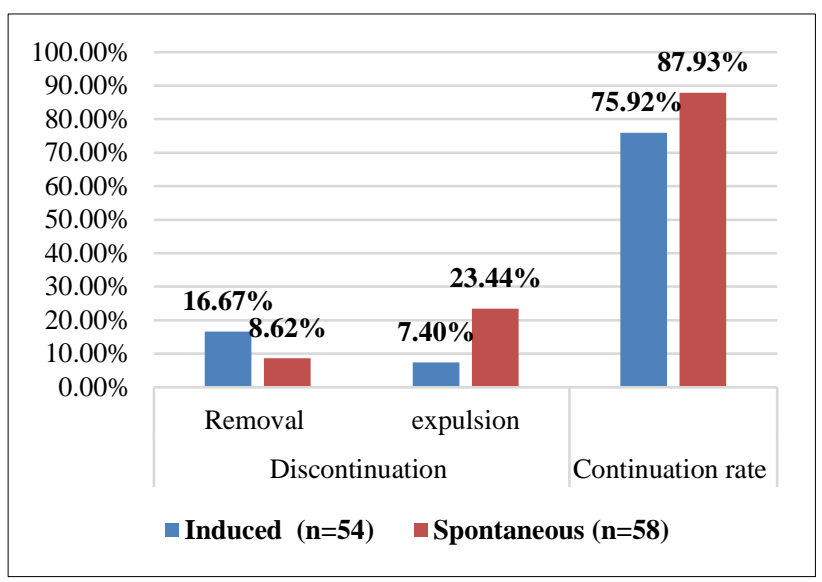

Figure 2: Association of method of abortion and continuation rate.

Out of 112, $92(82.14 \%)$ were satisfied. There was no statistically significant difference in continuation and satisfaction rate by device type.

Table 1: Studies on immediate post-abortal IUCD insertion.

\begin{tabular}{|lllllll|}
\hline \multirow{2}{*}{$\begin{array}{l}\text { Study } \\
\text { Tyllett et } \mathrm{al}^{3}\end{array}$} & $\begin{array}{l}\text { Type of abortion } \\
\text { MTOP*/STOP*** }\end{array}$ & $\begin{array}{l}\text { Percentage } \\
\text { Expulsion }\end{array}$ & PID & Pregnancy & Perforation & $\begin{array}{l}\text { Continuation } \\
\text { rate }\end{array}$ \\
\hline Bednarek et al $^{4}$ & STOP & 15.4 & NR & 2.3 & NR & NR \\
\hline WHO $^{5}$ & STOP & 5 & 1.9 & 0.4 & 0 & 92.3 \\
\hline Drey et al $^{6}$ & STOP & 4.4 & NR & NR & NR & 61 \\
\hline Shimoni et al $^{7}$ & MTOP & 0.8 & NR & NR & NR & 93.5 \\
\hline Saav et al & MTOP & 12 & NR & NR & NR & 69 \\
\hline Dewan R et al & MTOP & 9.7 & 0 & 0 & 0 & 67.7 \\
\hline Present study & MTOP and STOP & 7.4 & 1.8 & 0 & 0 & 72.2 \\
\hline
\end{tabular}

*MTOP: medical termination of pregnancy, **STOP: surgical termination of pregnancy.

\section{DISCUSSION}

The intrauterine device is an effective long lasting and reversible method of birth control with cumulative pregnancy rate of less than 1 per 100 women within first year of use. According to WHO (2015) insertion of IUCD can be done if abortion is complete. GOI has recently introduced promoted PAIUCD in National Family Planning Program. Irregular bleeding and pain are the most common reasons stated for the discontinuation of IUD use. The higher expulsion and lower continuation rates after medical abortion, compared to the rates after 
surgical abortion, may be due to more cramping and bleeding, which occur more often after medical abortion, causing downward displacement of the IUD. Most (53 out of 112) of the women belongs to upper lower socioeconomic status and $84(75 \%)$ were housewives.

Socio-demographic profile of women in this study is being representative of the total abortion seeking population catered by tertiary care public hospital of North India HMB were reported by 14 out of 112 women during 6 months follow up. HMB responded to hemostatic agent in all the cases except one in whom IUCD removal was done to relieve symptoms. In this study 5 women requested removal of IUCD due to inter menstrual bleeding not responding to medical management. Clinical outcome of various studies listed below (Table1).

According to Arowojolu et al heavy bleeding during menstruation was more common in $\mathrm{CuT} 380 \mathrm{~A}$ as compare to CuT375 users (5\% and $4 \%$ respectively). ${ }^{10}$ Celen $\mathrm{S}$ et al showed the main side effect of IUD usage are prolonged or excessive bleeding and abdominal pain during menstruation and reported rate of removal due to bleeding/pain was 3.3 per 100 women per year. This rate was higher than the majority of previously reported studies. ${ }^{11}$

PID was observed in 2 case at $3^{\text {rd }}$ month follow up and in 1 case at 6 months follow-up visit. They were treated with antibiotic on an outpatient basis and one woman had IUD removal. The trial of IUCD insertion by Stanwood et al, immediately following induced abortion reported lower pelvic inflammatory disease rate $(0.4$ per 100 woman-years). ${ }^{12}$ In present study at 6 months follow-up visits, there were no case of perforation found. Pohjoranta et al also reported no case of uterine perforation after IUD insertion. ${ }^{13}$

Failure rate after first was $0.96 \%$ and second trimester abortion was $12.5 \%$ but the difference is insignificant. Failure rate not differ on the basis of type of IUCD, method of abortion (medical/surgical) and type of abortion (spontaneous/induced). The IUCD is among the most effective reversible contraceptive methods; the failure rate with typical use is 0.1 to $0.8 \%$ in the first year, which is similar to the failure rate with female sterilization. ${ }^{14}$

In present study the cumulative continuation rate was $82.14 \%$ at 6 months follow-up visit. Drey EA also found high rates of continuation and satisfaction among women who had undergone immediate post-abortion IUD insertion; $74.2 \%$ women reported continuing the IUD. However, the mean time to follow-up in this study was only 8 weeks 6 . In the present study there were total of 6 IUCD expulsions out of 112 insertions, 5 expulsions out of 104 insertions following $1^{\text {st }}$ trimester $(4.80 \%)$ abortion and 1 expulsion out of 8 insertions $(12.5 \%)$ following $2^{\text {nd }}$ trimester abortion.
A recent study from California showed $2.1 \%$ expulsions with mean time of 9.5 months. Drey EA et al, found one $(0.8 \%)$ after a first trimester and four $(3 \%)$ after secondtrimester abortions. ${ }^{6}$ Bednarek et al, found $3.2 \%$ expulsion rate of $\mathrm{CuT} 380 \mathrm{~A}$ after first-trimester uterine aspiration at 6 months follow-up. ${ }^{4}$ WHO study were conducted related to immediate IUD insertion after first trimester surgical termination of pregnancy found expulsion rate at 24 months varied from $4.4 \%$ to $13.2 \% .^{5}$ Women satisfaction with the CuT380A and CuT375 insertion were $82.14 \%$. On statistical analysis the difference in level of satisfaction with IUCD use was not statistically significant $(p=1.00)$ by Fisher's exact test. Our findings support prior studies that show high rates of continuation and satisfaction with immediate post abortion IUD insertion.

McNicholas et al, also found high rates of continuation and satisfaction among women who had undergone immediate post abortion IUD insertion; $74.2 \%$ women reported continuing the IUD and $93.8 \%$ of those women reported being satisfied. The safety and efficacy of IUDs, as well as high rates of satisfaction and continuation, have been clearly demonstrated. ${ }^{15}$

\section{CONCLUSION}

- Early insertion of IUCD after abortion is safe, effective and well tolerated by the women. Immediate post abortion IUCD insertion provides a good opportunity to achieve long term contraception with minimal discomfort to the women.

- Clinical outcome of post abortion IUCD is not affected by type of copper containing IUCD i.e. $\mathrm{Cu} 380 \mathrm{~A}$ and Cu375.

- Intrauterine device expulsion rates are not affected by type of abortion, method of abortion and period of gestation. IUCD expulsion rates are higher in copper 380A IUCD as compared to copper 375 IUCD.

- There is high rates of continuation and satisfaction among women who had undergone immediate post abortion IUD insertion.

Funding: No funding sources

Conflict of interest: None declared

Ethical approval: The study was approved by the Institutional Ethics Committee

\section{REFERENCES}

1. Behera D, Bharat S, Gawde NC. Induced abortion practices in an Urban Indian slum: exploring reasons, pathways and experiences. J Family Reprod Health. 2015;9(3):129-35.

2. Schreiber CA, Sober S, Ratcliffe S, Creinin M. Ovulation resumption after medical abortion with mifepristone and misoprostol. Contracept. 2015;84:230-3.

3. Gillett PG, Lee NH, Yuzpe AA, Cerskus I. A comparison of the efficacy and acceptability of the 
Copper-7 intrauterine device following immediate or delayed insertion after first-trimester therapeutic abortion. Fertil-Steril. 1980;34:121-4.

4. Bednarek PH, Creinin MD, Reeves MF. Postaspiration IUD randomization (PAIR) study trial group. immediate versus delayed IUD insertion after uterine aspiration. N Eng J Med. 2011;364(23):220817.

5. World Health Organization Task Force on Intrauterine Devices for Fertility Regulation. IUD insertion following termination of pregnancy: a clinical trial of the TCu 220C, Lippes loop D, and copper 7. Stud Fam Plann. 1983;14:99-108.

6. Drey EA, Reeves MF, Ogawa DD, Sokoloff A, Darney PD, Steinauer JE Insertion of intrauterine contraceptives immediately following first- and second-trimester abortions. Contracept. 2009;79(5):397-402.

7. Shimoni N, Davis A, Ramos ME, Rosario L, Westhoff C. Timing of copper intrauterine device insertion after medical abortion. Obstet Gynecol. 2011;118:623-8.

8. Saav I, Stephansson O, Gemzell-Danielsson K. Early versus delayed insertion of intrauterine contraception after medical abortion: a randomized controlled trial. PloS One. 2012;7:e48948.

9. Dewan R, Nivedita, Mittal A, Dewan A. Early IUD insertion after medically induced abortion. Eu J Contracept Reprod Health Care. 2018;23:231-6.

10. Arowojolu AO, Otolorin EO, Ladipo OA. Performances of copper $\mathrm{T} 380 \mathrm{~A}$ and multiload copper 375/250 intrauterine contraceptive devices in a comparative clinical trial. Afr J Med Sci. 1995;24:59-65.

11. Celen S. Immediate post-placental insertion of an intrauterine contraceptive device during cesarean section. Contracept. 2011;84(3):240-3.

12. Stanwood NL, Grimes DA, Schulz KF. Insertion of an intrauterine contraceptive device after induced or spontaneous abortion: a review of evidence. $\mathrm{Br} \mathrm{J}$ Obstet Gynaecol. 2001;108:1168-73.

13. Pohjoranta E, Mentula M, Gissler M, Suhonen S, Heikinheimo O. Provision of intrauterine contraception in association with first trimester induced abortion reduces the need of repeat abortion: first- year results of a randomized controlled trial. Hum Reprod. 2015;30:2539-46.

14. Trussell J. Contraceptive failure in the United States. Contracept. 2004;70:89-96.

15. McNicholas C, Hotchkiss T, Madden T, Zhao Q, Allsworth J, Peipert JF. Immediate post-abortion intrauterine device insertion: continuation and satisfaction. Womens Health Issues. 2012;22(4):e365-e369.

Cite this article as: Dewan R, Rani P. Clinical outcome of post-abortion intrauterine contraceptive device insertion. Int J Reprod Contracept Obstet Gynecol 2020;9:2288-92. 